\title{
UPAYA PENINGKATKAN KESEJAHTERAAN SOSIAL ANAK JALANAN
}

\author{
Oleh: \\ Tundzirawati, Binahayati Rusyidi, \& Nurliana Cipta Apsari \\ Email: \\ tundzirawati04@gmail.com; titi.rusyidi06@gmail.com; nurliana.apsari@gmail.com
}

\begin{abstract}
ABSTRAK
Masalah anak jalanan merupakan hal yang sangat komplek penyebabnya. Setiap tahunnya jumlah anak jalanan selalu meningkat. Anak jalanan adalah anak yang berada dijalanan baik secara terpaksa maupu suka rela berada di jalan baik bekerja maupun tidak bekerja. Penyebab adanya anak jalanan dapat karena kondisi ekonomi, kondisi internal keluarga, lingkungan sosial, bencana, dan lain sebagainya. Semua anak berhak mendapatkan kesejahteraan demi tercapainya masa depan yang gemilang, begitu pula dengan anak jalanan memiliki hak yang sama dengan anak yang lain. kesejahteraan sosial anak adalah kondisi terpenuhinya kebutuhan material, spiritual, dan sosial anak agar dapat hidup layak dan mampu mengembangkan diri, sehingga dapat melaksanakan fungsi sosialnya. Upaya pemerintah dalam meningkatkan kesejahteraan sosial anak di Indonesia adalah dengan adanya Program Kesejahteraan Sosial Anak (PKSA)

Program Kesejahteraan Sosial Anak (PKSA) merupakan pelayanan sosial untuk memenuhi kebutuhan anak meliputi subsidi kebutuhan dasar, aksesibilitas pelayanan sosial, penguatan orang tua/keluarga dan lembaga kesejahteraan sosial. Lembaga kesejahteraan sosial anak yang menyelenggarakan pelayanan kesejahteraan sosial bagi anak jalanan, seperti rumah singgah atau LKSA (Lembaga Kesejahteraan Sosial Anak).

Upaya yang dilakukan pemerinah untuk menanggulangi serta mengurangi jumlah anak jalan yang ada di Indonesia. Dari PKSA (Program Kesejahteraan Sosial Anak) yang didirikan oleh pemerintah adalah upaya pemenuhan/subsidi kebutuhan dasar (akte lahir), pemberian makanan tambahan, memberikan pendidikan, serta memberikan jalan untuk kembali kepada orangtua.
\end{abstract}

KATA KUNCI: Kesejahteraan Sosial, Anak Jalanan, PKSA (Program Kesejahteraan Sosial Anak)

\section{PENDAHULUAN}

Anak adalah investasi dan harapan masa depan bangsa serta sebagai penerus generasi dimasa mendatang. Dalam siklus kehidupan, masa kanak-kanak merupakan fase dimana anak mengalami tumbuh kembang yang menentukan masa depannya. Perlu adanya optimalisasi perkembangan anak, karena selain krusial juga pada masa itu anak membutuhkan perhatian dan kasih sayang dari orang tua atau keluarga sehingga secara mendasar hak dan kebutuhan anak dapat terpenuhi secara baik. Anak seyogyanya harus dapat tumbuh dan berkembang menjadi manusia yang sehat jasmani dan rohani, cerdas, bahagia, bermoral tinggi dan terpuji, karena dimasa depan mereka merupakan aset yang akan menentukan kualitas peradaban bangsa.

Anak jalanan merupakan akibat langsung dari krisis diberbagai bidang, yang saat ini masih menjadi fenomena sosial di kota-kota besar. Anak jalanan adalah anak yang menghabiskan sebagian besar waktunya untuk melakukan kegiatan hidup sehari-hari di jalanan, baik untuk mencari nafkah atau berkeliaran di jalan dan tempat-tempat umum lainnya (Departemen Sosial RI, 2005: 5). 
Menurut hasil survei dan pemetaan sosial anak jalanan pada tahun 1999 jumlah anak jalanan mencapai 39.861 anak. Pada tahun 2002 jumlah anak jalanan mengalami peningkatan lebih dari 100\% dibandingkan angka tahun 1999. Menurut hasil Susenas yang diselenggarakan dengan kerjasama BPS dan Pusdatin Kesos pada tahun 2002 jumlah anak jalanan sebanyak 94.674 Anak. Pada tahun 2009 anak jalanan meningkat menjadi 230.000 anak (BPS 2009). Pada tahun 2014 meangalami peningkatan dua kali lipat dari tahun 2009 menjadi 420.000 anak janalan (Kemensos RI).

Hal yang dirasakan oleh anak jalanan tidaklah seindah dan semudah yang dijalani anak-anak pada umumnya. Mereka harus hidup ditengah kekerasan kota-kota besar yang tidak aman dan tidak bersahabat bagi anak jalanan. Keberadaan mereka berada di jalanan sebagian besar disebabkan karena faktor ekonomi. Mereka terpaksa turun ke jalan karena harus mencari nafkah untuk dirinya sendiri. Bahkan tak jarang banyak anak jalanan yang turun ke jalan disebabkan adanya paksaan dari orangtua untuk memenuhi kebutuhan orangtuanya. Lebih miris lagi anak jalanan yang turun ke jalan karena paksaan dari preman atau orang dewasa yang bukan keluarganya. Dalam kasus seperti ini, jika mereka tidak membawa uang sebesar yang disuruh oleh orangtua atau orang dewasa yang bukan keluarganya (preman) mereka akan mendapatkan hukuman berupa tindak kekerasan fisik, psikologis, maupun seksual. Selain sebab ekonomi, anak yang turun ke jalan disebabkan karena dibuang oleh orangtuanya sendiri. Ada pula yang turun ke jalan disebabkan mengikuti teman atau kabur dari rumah.

Citra negatif yang selalu diterima oleh anak jalanan menjadikan anak jalanan dipandang sebelah mata. Mendapatkan penghinaan dari masyakat dapat membuat kondisi psikologis anak tertanggu. Mungkin anak dapat merasa malu, tidak percaya diri dan lain sebagainya.

Banyak anak jalanan yang tidak memiliki tempat tinggal, mereka tidur di tempat umum seperti terminal, pasar, stasiun kereta api, pertokoan, di bawah jembatan layang, di jembatan penyebrangan dan lain-lain. Sudah bukan pemandangan asing bila di tempat-tempat tersebut tergeletak banyak anak jalanan yang hanya menumpang tidur dengan beralaskan koran atau kardus bahkan ada yang tidak memakai alas tidur sama sekali. Atap rumah mereka adalah langit, tidak ada tempat bernaung dari terpaan hujan dan teriknya matahari.

Bukan itu saja penderitaan mereka. Kebutuhan akan makanan belum tentu dapat terpenuhi setiap hari dengan gizi dan kebersihan yang baik. Sudah dapat makan satu kali dalam satu hari pun sudah beruntung. Selain itu mereka bergelut dengan kotor dan debu-debu jalanan. Mereka pun harus selalu siaga akan adanya Satpol PP yang kapan saja bisa mengakap mereka. Penangkapan paksa dan perlakuan kekerasan membuat anak jalanan lebih memilih lari dari tangkapan Satpol PP.

Banyak resiko yang sewaktu-waktu dapat menimpa mereka. Anak jalanan sangat beresiko menjadi korban eksploitasi. Eksploitasi yang terjadi pada anak jalanan berasal dari orang dewasa yang bukan merupakan keluarganya (preman dll) dan juga dapat berasal dari keluarganya sendiri (orangtua). Mereka di eksploitasi untuk bekerja mencari uang sebanyak-banyaknya dengan cara seperti mengamen, mengemis, menjual asongan, dan mungkin juga di eksploitasi untuk menjual dirinya.

Tindak kekerasan juga adalah resiko yang mungkin terjadi kepada anak jalanan. Tidak memiliki perlindungan dari orang dewasa, anak jalanan sangat rentan mendapatkan tindak kekerasan baik fisik, mental, maupun seksual. Tindak kekerasan ini pula dapat dilakukan oleh keluarganya sendiri. Selain itu anak jalanan juga rentan menjadi korban pelecehan seksual bahkan oleh keluarga atau orangtuanya sendiri.

Anak jalanan tumbuh dan berkembang dengan latar kehidupan jalanan dan akrab dengan kemiskinan, penganiayaan, dan hilangnya kasih sayang, sehingga memberatkan psikologis dan membuatnya berperilaku negatif. Anak jalanan senantiasa berada dalam situasi yang mengancam perkembangan fisik, mental dan sosial bahkan nyawa mereka. Di dalam situasi kekerasan yang dihadapi secara terus-menerus dalam perjalanan hidupnya, maka pelajaran itulah yang melekat dalam diri anak jalanan dan membentuk kepribadian mereka. Ketika mereka dewasa, besar kemungkinan mereka akan menjadi salah satu pelaku kekerasan. 
Selain memiliki resiko yang tinggi, kebanyakan anak jalanan juga tidak melanjutkan pendidikannya karena harus mencari nafkah demi menyambung hidup. Anak jalanan pun biasanya memiliki perilaku yang kurang baik seperti "ngelem", melakukan seks bebas, minum minuman beralkohol, penggunaan obat terlarang dan lain-lain. Seperti yang dilakukan F (15) anak jalanan di Kota Semarang yang tertangkap razia polisi kedapatan sedang ngelem di Lapangan Simpang lima. Kepada polisi F mengaku sudah dua bulan yang lalu ia melakukan kegiatan itu yang dia pelajari sejak ia mulai bergaul bersama temannya sesama pengamen yang sering nongkrong di Lapangan Simpanglima. Dalam sehari, bocah yang berhenti sekolah di kelas 1 SMP ini bisa menghabiskan uang Rp. 13.000; (tiga belas ribu rupiah) hanya untuk membeli lem di toko bangunan. Baginya, lem bisa membuatnya berfantasi dan melupakan segala beban hidup. (TRIBUNNEWS.COM diakses pada 18 Desember 2014 pukul 02:55 WIB)

Angka anak jalanan yang sangat tinggi saat ini dengan berbagai resiko yang mereka hadapi sangat perlu berbagai pihak untuk terlibat dalam membantu membela hak-hak mereka, sebab tongkat estafet kepemimpinan bangsa ini ada di tangan mereka.

\section{KESEJAHTERAAN SOSIAL ANAK JALANAN}

Kesejahteraan sosial menurut definisi Undang Undang no 11 tahun 2009 adalah kondisi terpenuhinya kebutuhan material, spiritual, dan sosial warga negaranya. Dalam pedoman pelaksanaan PKSA Kementerian Sosial (2010), kesejahteraan sosial anak adalah kondisi terpenuhinya kebutuhan material, spiritual, dan sosial anak agar dapat hidup layak dan mampu mengembangkan diri, sehingga dapat melaksanakan fungsi sosialnya.

Demi mencapai kesejahteraan anak, maka anak harus mendapatkan hak-haknya. Hak anak adalah bagian dari hak asasi manusia yang wajib dijamin, dilindungi, dan dipenuhi oleh orangtua, keluarga, masyarakat, pemerintah dan negara agar anak terlindung dari kekerasan dan penyalahgunaan. Hak anak bertujuan untuk memastikan bahwaa setiap anak memiliki kesempatan untuk mencapai pontensi mereka secara penuh.

Hak dasar seorang anak adalah mendapatkan kesempatan untuk hidup, mendapatkan kesempatan untuk tumbuh dan berkembang, mendapatkan kesempatan untuk berpartisipasi, dan mendapatkan perlindungan. Hak-hak dasar itu semua tidak didapatkan oleh para anak jalanan.

Guna meningkatkan kesejahteraan anak jalanan, kita harus memperhatikan agar semua hakhak mereka terpenuhi. Berdasarkan Konvensi Hak Anak PBB Tahun 1989, ada 10 hak yang harus diberikan untuk anak kita. Berikut di antaranya:

1. Hak untuk bermain

Anak jalanan tidak mendapatkan haknya untuk bermain sebab mereka menghabiskan waktunya untuk bekerja mencari nafkah. Tempat bermain anak jalanan adalah di jalanan. Jalan adalah tempat untuk bermain, mencari nafkah, dan menghabiskan waktu untuk istirahat. Pemerintah telah menyediakan program bagi anak jalanan berupa rumah singgah atau LKSA (Lembaga Kesejahteraan Sosial Anak). Rumah singgah atau LKSA ini dapat menjadi tempat bermain yang dapat mendidik anak-anak jalanan dari segi pendidikan maupun moral serta agama.

2. Hak untuk mendapatkan pendidikan

Anak jalanan berhak untuk mendapatkan pendidikan. Banyak anak jalanan yang putus sekolah karena harus bekerja mencari uang. Pendidikan merupakan hal yang penting demi keberlangsungan masa depan anak termasuk masa depan anak jalanan. Meskipun sudah adanya bantuan pemerintah dalam bidang pendidikan yaitu BOS (Bantuan Operasional Sekolah) banyak anak jalanan yang putus sekolah karena tidak memiliki biaya dan lebih memilih mencari nafkah untuk dirinya dan keluarganya. Pemeritah melalui PKSA (Program Keseajahteraan Sosial Anak) melakukan peningkatan aksesbilitas terhadap pelayanan sosial dasar yang meliputi: pengembangan jaringan kerja, pemberian life skill, pelaksanaan pendidikan formal dan nonformal, rujukan ke pendidikan (formal, non formal, maupun in formal), penyediaan peralatan 
dan perlengkapan sekolah, monitoring dan evaluasi peserta didik, dan layanan remedial (pendidikan formal yang sesuaii dengan standar pelayanan minimal pendidikan nasional). Dengan adanya program ini diharapkan pemerintah dapat membantu anak jalanan untuk mendapatkan pelayanan dan fasilitas pendidikan lebih baik lagi. Sehingga membuat masa depan anak jalanan menjadi lebih baik.

3. Hak untuk mendapatkan perlindungan

Anak jalanan sangat memerlukan hak mendapatkan perlindungan. Banyak resiko yang berbahaya yang akan mengancam anak jalanan. Anak jalanan beresiko mendapatkan tindak kekerasan yang dapat berdapat negatif bagi dirinya. Meskipun perlindungan anak telah diatur oleh undangundang tetapi tindak kekerasan masih saja sering terjadi kepada anak jalanan. Pemerintah dalam PKSA (Program Kesejahteraan Sosial Anak) melalui LKSA (Lembaga Kesejahteraan Sosial Anak) atau rumah singgah akan melakukan perlindungan serta advokasi bagi anak jalanan yang menjadi korban tindak kekerasan.

Selain rumah singgah pemerintah pun membuat Satuan Tugas Perlindungan Anak (Satgas PA) di setiap RT/RW/komunitas untuk mencegah terjadinya tindak kekerasan pada anak. Setiap Satgas dibekali dengan pengetahuan dan keterampilan dalam perlindungan anak. Satgas ini diharapkan bisa mencegah anak yang rentan menjadi korban, mendukung anak yang bermasalah, dan melindungi anak yang menjadi korban dengan membuka konsultasi, bimbingan, pendampingan, dan pembinaan.

4. Hak untuk mendapatkan nama (identitas)

Anak jalanan berhak memiliki identitas (seperti nama dan akte kelahiran), berhak mengetahui dan diasuh oleh orangtuanya. Sebab anak jalanan turun ke jalan salah satunya adalah karena dibuang oleh orangtuanya, berarti banyak anak jalanan yang sudah dirampas haknya oleh orangtuanya sendiri. Pemerintah dalam PKSA (Program Kesejahteraan Sosial Anak) memberikan bantuan sosial atau subsidi hak dasar dengan membantu pembuatan akte kelahiraan serta peningkatan tanggung jawab orang tua atau keluarga dalam pengasuhan dan perlindungan anak. Apabila pengembalian anak kepada orang tua tidak memungkinkan maka anak jalanan dapat singgah di LKSA atau rumah singgah tersebut.

5. Hak untuk mendapatkan status kebangsaan

Anak jalanan juga memiliki hak untuk mendapatkan status kebangsaan. Semua anak jalanan yang ada di Indonesia memiliki status kewarganegaraan warga negara Indonesia.

6. Hak untuk mendapatkan makanan

Banyak anak jalanan yang tidak dapat mendapatkan makanan. Setiap hari mereka harus bekerja keluar keringat terleabih dulu untuk mendapatkan makanan. Maka pemerintah melalui PKSA (Program Kesejahteraan Sosial Anak) memberikan pelayanan peningkatan nutrisi atau gizi keluarga melalui pemahaman pola makan sehat, pengenalan keanekaragaman makanan sehat, perencanaan menu makan sehat keluarga, dan pemberian makanan tambahan.

7. Hak untuk mendapatkan akses kesehatan

Anak jalanan sulit untuk mendapatkan akes pada pelayanan kesehatan karena mereka berasal dari keluarga dengan ekonomi yang sangat bawah. Maka pemerintah melalui Program Kesejahteraan Sosial Anak (PKSA) memberikan akses pelayanan kesehatan dasar melalui pemahaman pola hidup sehat dan pemberian SKTM atau Jaminan Kesehatan Masyarakat atau Gakin.

8. Hak untuk mendapatkan rekreasi

Hak untuk mendapatkan rekreasi anak jalanan tidak terpenuhi. Waktu mereka habis digunakan untuk mencari nafkah di jalan. Pemerintah pun tidak menfasilitasi anak jalanan untuk memenuhi hak mendapatkan rekreasi.

9. Hak untuk mendapatkan kesamaan (non diskriminasi) 
Anak jalanan sama dengan anak yang lainnya memiliki hak yang sama pula. Maka pemerintah membuat PKSA (Program Kesejahteraan Sosial Anak) dan menyediakan LKSA (Lembaga Kesejahteraan Sosial Anak) untuk dapat memenuhi kebutuhan anak jalanan.

10. Hak untuk memiliki peran dalam pembangunan

Anak jalanan pun memiliki hak untuk meamiliki peran dalam pembangunan. Dengan adanya PKSA dan LKSA, anak jalanan dapat di latih secara soft skills maupun secara pengatahuannya sehingga mereka juga dapat mempengaruhi proses pembangunan kini dan nanti.

Rumah singgah sebagai perantara anak jalanan dengan pihak-pihak yang akan membantu mereka serta wadah bagi para anak jalanan membela hak-haknya. Rumah singgah merupakan proses informal yang memberikan suasana pusat realisasi anak jalanan terhadap sistem nilai dan norma di masyarakat.

\section{PENUTUP}

Anak jalanan dapat diakibatkan dari kurangnya kondisi ekonomi sehingga memaksa mereka untuk mencari nafkah di jalan. Selain itu juga disebabkan adanya paksaan dari orang dewasa untuk mencari uang, dibuang oleh orangtuanya sehingga ia tidak memiliki siapa-siapa dan harus tinggal dijalan serta terbawa atau mengikuti temannya yang sudah berada di jalanan.

Dalam upaya meningkatkan kesejahteraan sosial pada anak jalanan, pemerintah membuat Program Kesejahteraan Sosial Anak (PKSA). PKSA Kementerian Sosial RI adalah upaya yang terarah, terpadu dan berkelanjutan yang dilakukan pemerintah dan masyarakat dalam bentuk pelayanan sosial untuk memenuhi kebutuhan anak meliputi subsidi kebutuhan dasar, aksesibilitas pelayanan sosial, penguatan orang tua/keluarga dan lembaga kesejahteraan sosial. Lembaga kesejahteraan sosial anak yang menyelenggarakan pelayanan kesejahteraan sosial bagi anak jalanan, seperti rumah singgah atau LKSA (Lembaga Kesejahteraan Sosial Anak). Melalui PKSA hampir seluruh hak anak dapat dipenuhi. Selain itu pemerintah mendirikan Satuan Tugas Perlindungan Anak (Satgas PA) untuk melindungi, mencegah dan menangani anak yang rentan mengalami tindak kekerasan.

\section{REFERENSI}

Isbandi Rukminto Adi. Kesejahteraan Sosial, Pembangunan Sosial dan Intervensi Komunitas. Jakarta:Lembaga Penerbit Fakultas Ekonomi Universitas Indonesia. 2003, hlm. 4.

Suharto Edi. Membangun Masyarakat Memperdayakan Rakyat: Kajian Strategi Pembangunan Keseajahteraan Sosial dan Pekerja Sosial. Bandung: Refika Aditama. 2005, hlm. 1-3.

Pedoman PKSA (Program Kesejahtearaan Sosial Anak) Kementerian Sosial Republik Indonesia.

Kementerian Sosial. Jakarta

Undang-Undang

Republik Indonesia. 2003. Undang-Undang No. 23 Tahun 2003 Tentang Perlindungan Anak.

Lembaran Negara RI Tahun 2003. Jakarta.

Republik Indonesia. 1979. Undang-Undang No. 4 tahun 1979 Tentang Kesejahteraan Anak.

Lembaran Negara RI Tahun 1979. Jakarta.

Republik Indonesia. 1974. Undang-undang No. 6 Tahun 1974 Tentang Ketentuan-ketentuan Pokok Kesejahteran Sosial. Lembaran Negara RI Tahun 1974. Jakarta.

Artikel Online

Affifah, Ifah. 27 Februari 2013. Darurat kekerasan, satgas perlindungan anak hadir ditingkat RT /RW (Online), (http://www.radioaustralia.net.au/Indonesian/2013-02-27/darurat-kekerasansatgas-perlindungan-anak-hadir-ditingkat-rt-rw/1094086 di akses 18 Desember 2014)

Hamid, Almisar. 17 Juni 2014. Perlindungan Sosial Anak Dan Masalahnya (Online), 
(http://www.kemsos.go.id/modules.php?name=Content\&pa=showpage \&pid=16 diaskes pada 16 Desember 2014)

Hariyono, Tri. Membangun Kebijakan Yang Humanis Dalam Penanganan Masalah Anak Jalanan (Online), (http://www.academia.edu/4810679/Kebijakan_Anak_Jalanan diakses pada 16 Desember 2014).

Imob Educare. 4 Juli 2014. 2014: Indonesia Bebas dari Anak Jalanan? (Online), (http://www.imobeducare.com/story/2014-Indonesia-bebas-dari-anak-jalanan diakses pada 16 Desember 2014).

Kemensos. Sekilas Tentang Masalah Anak (Online), (http://rehsos.kemsos. go.id/ modules.php?name=Content\&pa=showpage \&pid=5 diakses pada 16 Desember 2014).

Radlis, Muh. 16 Desember 2013. Ngelem Bisa Bikin Saya Ketemu Artis Agnes Monica (Online), (http://www.tribunnews.com/regional/2013/12/16/ngelem-bisa-bikin-saya-ketemu-artis-agnesmonica, diakses pada 18 Desember 2014)

Republika. 02 Agustus 2013. 10 Hak Anak Indonesia, Sudahkah Anda Memberikan Ini? (Online), (http://www.republika.co.id/berita/humaira/samara/13/08/01/mquqn1-10-hak-anak-Indonesiasudahkah-anda-memberikan-ini di akses 16 Desember 2014).

Reyta. Sakti Peksos (PKSA) (Online), (http://kapanjadibeda.wordpress.com/program-kesejahteraansosial-anak-pksa/ diakses 16 Deseamber 2014).

Suahepi, Epi. 14 April 2014. Upaya Penanganan Anak Jalanan (Online), (http://pecintapena.wordpress.com/2011/06/04/upaya-penanganan-anak-jalanan/ di akses pada 16 Desember 2014).

Tommy. 27 Agustus 2010. Kekerasan Terhadap Anak Jalanan (Online), (http://sdc.kemsos.go.id/modules.php?name=News\&file=article\&sid=20, diakses 18 Desember 2014). 